\title{
Socio-Demographic Characteristics Influencing Uptake of Screening for Cervical Cancer in Women Aged 18-49 Years in Imenti North Sub-county, Meru County, Kenya
}

\author{
Mutuma Agnes Muthoni ${ }^{1}$, Otieno George Ochieng ${ }^{2}$, Kei Robert Mburugu ${ }^{3}$, Ndege Samson ${ }^{3}$, \\ Ndwiga Taratisio ${ }^{3}$, Gacheri Rose ${ }^{4}$ \\ ${ }^{1}$ Medical Training College, Meru, Kenya \\ ${ }^{2}$ School of Public Health, Kenyatta University, Nairobi, Kenya \\ ${ }^{3}$ School of Public Health, Moi University, Eldoret, Kenya \\ ${ }^{4}$ Santao Media College, Nairobi, Kenya
}

\section{Email address:}

agnesmutuma@yahoo.com (M. A. Muthoni),otienogo@gmail.com (O. G. Ochieng), mburugukei@gmail.com (K. R. Mburugu), ndegekip@yahoo.com (N. Samson), taratisiondwiga@gmail.com (N. Taratisio), rosemburugu@gmail.com (G. Rose).

\section{To cite this article:}

Mutuma Agnes Muthoni, Otieno George Ochieng, Kei Robert Mburugu, Ndege Samson, Ndwiga Taratisio, Gacheri Rose. SocioDemographic Characteristics Influencing Uptake of Screening for Cervical Cancer in Women Aged 18-49 Years in Imenti North Sub-county, Meru County, Kenya. Science Journal of Public Health. Vol. 4, No. 2, 2016, pp. 94-99. doi: 10.11648/j.sjph.20160402.13

\begin{abstract}
Background: Cervical cancer continues to kill approximately 274,883 women globally every year, despite robust programs for the prevention and control of the disease. Kenya has an uptake of cervical cancer screening (3.2\%) compared to the National Cervical Cancer Prevention program target of 70\%. The purpose of this study was to determine the sociodemographic characteristics influencing uptake of cervical cancer screening in Imenti North Sub-County. Methods: This was institution-based descriptive cross- sectional study conducted among 422 randomly selected women aged 18-49 years attending general outpatient clinics in health facilities of Imenti North Sub-County, Kenya. Health Facilities were stratified based on functional levels to include county referral, health centers and dispensaries. Data was collected using interviewer administered questionnaire Characteristics influencing uptake of cervical cancer screening were analyzed using chi-square test and logistic regression to determine predictors for cervical cancer screening. Results: The study found out that the level of uptake for cervical cancer screening by the respondents was $15.2 \%$. However, the level of the uptake was lowest among women aged 18-25 (4.4\%) and women with primary level of education (11.6\%). In addition, the study found significant association between uptake and age ( $p$-value $<0.001)$. Other significant socio-demographic characteristics include marital status and level of education. Women in age category $42-49$ years were 6 times more likely to be screened compared to women aged 18-25 years $(p$-value $=0.022)$. Conclusion and recommendations: The level of uptake for cervical cancer screening by the respondents was $15.2 \%$. The main determinants of uptake of screening were age, marital status, occupation, and high level of education. It was recommended that Health Managers should conduct refresher seminars for health workers, increase facilities offering screening services and intensify community health education in order to increase uptake of cervical cancer screening.
\end{abstract}

Keywords: Cervical Cancer, Women of Reproductive Age, Socio-Demographic Characteristics,

Uptake of Cervical Cancer Screening

\section{Introduction}

Cervical cancer is the second most common cancer among women worldwide with an estimated 528000 new cases were reported in 2012 and an estimated 266000 deaths from cervical cancer worldwide [1]. While developed countries have reported outstanding progress in reduction of cervical cancer cases, progress is slow in the developing countries [1]. In sub-Saharan Africa, cervical cancer accounts for $22 \%$ of all cancers and it is the most common cause of cancer deaths among women [2]. Eastern Africa is ranked among the high risk regions with an incidence of 42.7 per 100000 and mortality of 27.6 in 100000 [1].

In Kenya cervical cancer is the second most frequent cancer among women with an estimated 2,454 new cases 
reported annually and cervical cancer related deaths being at 1,676. A major concern is that new cases are projected to rise to 4261 by the year 2025 [3]. The anticipated increase can be averted through health prevention habits such as practicing cervical cancer screening for women of reproductive age every 3 years. About $50 \%$ of women in reproductive age have been screened in developed nation's countries as compared to $5 \%$ in developing countries [4].

While screening can greatly reduce morbidity and mortality due to cervical cancer, cervical cancer screening coverage is quite low in Kenya with an estimated 3.2\% of women aged $18-69$ being screened every 3 years [5, 6]. More urban women $4.0 \%$ are screened as compared to rural women $2.6 \%[5,6]$. A study carried out at Kenyatta National Hospital (a referral hospital) reported that about 55\% of women often report to hospital when cancer is already at an advanced stage [7].

Reasons for low uptake are not well documented but studies have suggested that age, education, contraceptive use and being married are determinants of uptake of cervical cancer screening [8]. The Kenya national reproductive health policy attributes the low uptake to inadequate access to comprehensive reproductive organ cancer prevention, early detection and management services, limited information among communities of reproductive organs, delay in seeking healthcare among others [9]. These suggested reasons mainly apply to rural settings in developing countries. Women in these areas have limited access to health services because they live far away (more than $5 \mathrm{~km}$ ) from health facilities and cannot leave their homes or cannot afford to pay for travel. Those who do Pap smear may not turn up for results and probable treatment which interferes with the effectiveness of cervical cancer screening. Imenti North sub-county is one such rural setting where screening for cervical cancer uptake is low with $6.2 \%$ women having been screened between 2011-2013 [9]. Cervical cancer screening in the health facilities at Imenti North both public and private, is carried out by clinicians (nurses, clinical officers and doctors) trained in reproductive health services. Screening services are also supported by development partners such as the University of Nairobi, through its most at risk persons (MARPS) program, in the form of buying instruments and facilitating the clinicians while they carry out the mobile cervical cancer screening services. Records of cervical cancer cases in Imenti North are unavailable in the District Health Information System (DHIS). The County Hospital records indicate that new cases of cervical cancer are 2 in 1000 [10]. Out of the 43,018 Women of Reproductive Age (WRA) recorded in 2012, $2683(6.2 \%)$ were screened for cervical cancer between January 2011 to June 2013 [10]. Positive VIA/VILLI test was detected in 166 women (6.2\%) while 97 (3.4\%) were referred for full evaluation of cervical lesions suggestive of cervical cancer. With just $6.2 \%$ of the women having been screened, majority are still unaware of their status. Thus, despite the efforts by the government and other development partners to accelerate uptake of screening and early detection, diagnosis and appropriate management of cancer of the cervix at the healthcare facilities, uptake of cervical cancer screening has remained low [10]. The study seeks to identify and make emergent recommendations on those factors influencing uptake of cancer screening to women in Imenti North, Meru County. Knowledge of the factors that influence uptake cervical cancer screening helps in developing targeted interventions to increase utilization of screening services. Increased cervical cancer screening will eventually lead to decreased cases of cervical cancer. Policy makers and program planners can utilize information to develop policies that favour uptake as well as mobilize resources needed to enhance uptake of screening of cervical cancer.

\section{Methods}

\section{Setting and target population}

This was institution-based descriptive cross- sectional study carried out between 17th February and 4th March 2014. Data was obtained from a survey of women of reproductive age attending general outpatient clinics. The target number of women of reproductive age seeking cancer screening services was 43,018 in Imentin North sub-county. The Sub- County is served by 6 public health facilities and 11 privately owned health facilities. Marie Stopes and Family Care Options of Kenya are private facilities offering cervical cancer screening by Visual Inspection with Acetic Acid (VIA), Visual Inspection with Lugol's Iodine (VILI) and Pap smear. Consolidated health records of cancer screening services in Imenti Sub-County available at the Meru Level 5 Hospital indicate that 2733 were screened for cervical cancer between January 2011 and June 2013, thus uptake of cervical cancer screening for Imenti North is estimated to be $6.3 \%$.

Based on the Cochran's formula of sample size determination [11] and assuming a probability of finding a woman of reproductive age who had been screened to be 0.5 at $95 \%$ confidence interval [12], the sample size for this study was 384 women of reproductive age. This was then adjusted by $10 \%$ for non-response to obtain a final sample size of 422 women of reproductive age. Health facilities were then stratified according to their functional level to include one County hospital; two dispensaries and two private clinics. In each of the selected facility, all women of reproductive age who attended general outpatient clinic were systematically sampled using a predetermined interval. The facilities were assigned sample size based on the probability proportion to size based on the previous patient records. Data was collected using a questionnaire developed for this study based on the objectives and following an extensive literature review. The questionnaire sought information on sociodemographic and economic; knowledge of cervical cancer screening and risk factors; attitude towards screening uptake; and, health system factors.

Data collected was inspected, cleaned, coded and entered into Excel computer package for processing. Data was then exported to statistical package for social sciences (SPSS) version 20 for ease of analysis. Descriptive statistical tests (mean, median, and standard deviation) were used to 
summarize data according to the variables for the study. Association between variables was described using chisquare, and the strength of associations determined using logistic regression models. Statistical tests were done at the conventional level of accuracy $0.05(\mathrm{p}=0.05)$ and confidence interval of $95 \%$.

Ethical considerations included seeking approval to carry out research from the County Health Research Committee. Informed consent from all study participants that clearly explains to participants what the study was investigating and their required participation. Confidentiality and privacy was guaranteed to the participants by explaining to them any information obtained from them would be treated with utmost confidence and that privacy ensured during the session(s). That any information about the participant would have a number instead of a name thus ensuring anonymity. Autonomy was guaranteed with participants allowed to be engaged in the study at their own free will. They were allowed to withdraw in the course of the study if they so wish.

\section{Results}

\subsection{Socio Demographic Characteristics of the Respondents}

The highest percentage of respondents was in the age bracket 26-33 years while the lowest were 42-49 years. Majority of the respondents were married (72.5\%). Most of them had 1-2 children $(52.1 \%)$. The highest number of respondents had attained primary level of education (40.8\%) Most of the respondents were self-employed (51.4\%) and unemployed (14\%) as shown in table 1.

Table 1. Social-demographic characteristics of the respondents.

\begin{tabular}{llll}
\hline VARIABLE & & N & \% \\
\hline \multirow{4}{*}{ Age in complete years } & $18-25$ & 159 & 37.7 \\
& $26-33$ & 161 & 38.2 \\
& $34-41$ & 80 & 19 \\
Area of residence & Urban & 22 & 5.2 \\
Highest level of school & Rural & 199 & 47.2 \\
attended & Primary & 223 & 52.8 \\
& secondary & 172 & 40.8 \\
Marital status & Tertiary & 127 & 30.1 \\
& single & 123 & 29.1 \\
& Married & 116 & 27.5 \\
& 1-2 children & 306 & 72.5 \\
Number of children & 3-4 children & 220 & 52.1 \\
& 5 and more & 88 & 20.9 \\
Occupation & No children & 28 & 6.6 \\
& Formally Employed & 146 & 34.6 \\
& Self Employed & 217 & 51.4 \\
& Unemployed & 59 & 14 \\
\hline
\end{tabular}

\subsection{Uptake of Cervical Cancer Screening}

Among the respondents, $15.2 \%$ had been screened for cervical cancer of which $78 \%$ did so within the past 3 years. Majority of the respondents were screened at the Meru level 5 hospital (48\%) followed by Kithoka dispensary (24\%). Kithoka dispensary had most of the respondents screened during outreach services by Family Options Kenya but no screening was done at Kathithi dispensary because there was no skilled health worker. The reasons for not being screened included; respondents not yet decided (31.8\%), lack of knowledge about screening $(24.2 \%)$, pain during screening (11.8), shyness $(8.3 \%)$, distance to screening facility $(2 \%)$, unwelcoming health workers $(1.2 \%)$ and lack of spousal support $(1.7 \%)$. The table 2 shows the uptake of screening for selected health facilities.

Table 2. Distribution of screening per facility.

\begin{tabular}{|c|c|c|c|c|c|}
\hline \multirow{3}{*}{ FACILITY } & \multicolumn{2}{|c|}{ SCREENED } & \multicolumn{2}{|c|}{ IF YES, WHEN? } & \multirow[b]{2}{*}{ Total } \\
\hline & Yes & No & $\begin{array}{l}\text { Within } 3 \\
\text { years }\end{array}$ & $\begin{array}{l}\text { More than } 3 \\
\text { years }\end{array}$ & \\
\hline & $n(\%)$ & n(\%) & $n(\%)$ & n(\%) & \\
\hline $\begin{array}{l}\text { Meru level } 5 \\
\text { hospital }\end{array}$ & $26(9.6)$ & $245(90.4)$ & $23(88.5)$ & $3(11.5)$ & 271 \\
\hline $\begin{array}{l}\text { Kithoka } \\
\text { dispensary }\end{array}$ & $13(36.1)$ & $23(63.9)$ & $6(46.2)$ & $7(53.8)$ & 36 \\
\hline $\begin{array}{l}\text { Gakoromone } \\
\text { dispensary }\end{array}$ & $10(18.5)$ & $44(81.5)$ & $8(80)$ & $2(20)$ & 54 \\
\hline $\begin{array}{l}\text { Giaki } \\
\text { Dispensary }\end{array}$ & $10(45.5)$ & $12(54.5)$ & $7(70)$ & $3(30)$ & 22 \\
\hline $\begin{array}{l}\text { Kathithi } \\
\text { dispensary }\end{array}$ & $0(0)$ & $13(100)$ & $0(0)$ & $0(0)$ & 13 \\
\hline $\begin{array}{l}\text { Kiburine } \\
\text { dispensary }\end{array}$ & $2(14.3)$ & $12(85.7)$ & $1(50)$ & $1(50)$ & 14 \\
\hline Mariestopes & $1(50)$ & $1(50)$ & $1(100)$ & $0(0)$ & 2 \\
\hline $\begin{array}{l}\text { Family health } \\
\text { options kenya }\end{array}$ & $2(20)$ & $8(80)$ & $2(100)$ & 0 & 10 \\
\hline Total & $64(15.2)$ & $358(84.8)$ & $48(75)$ & $16(25)$ & 422 \\
\hline
\end{tabular}

\subsection{Self-Reported Risk Factors of Cervical Cancer}

Family planning methods used by the respondents were injectable (32.9\%) and pills (30.3\%) and no family planning method $(22.7 \%)$. The respondents who reported smoking cigarettes were $(3.6 \%)$ and those who had suffered from STI's in the previous one year $(14.9 \%)$. Table 3 present the result of the analysis of the self-reported risk factors

Table 3. Self-reported risk factors of cervical cancer.

\begin{tabular}{llll}
\hline VARIABLE & & N & \% \\
\hline & Injectables & 139 & 32.9 \\
& Pills & 128 & 30.3 \\
& Implants & 30 & 7.1 \\
& IUDs & 19 & 4.5 \\
Family Planning Method & Female Condom & 6 & 1.4 \\
& LAM & 1 & .2 \\
& Others & 3 & .7 \\
& None & 96 & 22.7 \\
Smoking status in the previous & Yes & 15 & 3.6 \\
one year & No & 407 & 96.4 \\
Sexually transmitted infections & Yes & 63 & 14.9 \\
(STI) the previous year & No & 359 & 85.1 \\
\hline
\end{tabular}




\subsection{Socio Demographic Characteristics Influencing Uptake of Cervical Cancer Screening}

There was a significant relationship between age and uptake of cervical cancer screening $(\mathrm{P}=0.001)$. The highest uptake of cervical cancer screening was by respondents within the age group $42-49$ years at $(31.8 \%)$ while the lowest uptake was by those in the age group 18-25 (4.4\%). There was a significant relationship between being married and uptake of screening with $(18 \%)$ of married women having undertaken screening compared to single women with $(7.8 \%)$ $(\mathrm{P}=0.009)$. Women with tertiary level of education had the highest rate of screening (22.8\%) while those with primary level of education had the lowest uptake (11.6\%), $(\mathrm{P}=0.020)$. Increasing parity was significantly associated with screening and women with three or more children had a higher uptake $(25.9 \%)$ than those with $1-2$ children $(13.6 \%)(\mathrm{P}=0.005)$. Formally employed women had the highest uptake to screening $(18.5 \%), \quad P$-value $=0.007)$. There was no significance difference between rural and urban residents $(\mathrm{P}=0.961)$.

In addition, women in age category 42-49 were 6 times more likely to be screened compared to women in age category 18-25 $(\mathrm{P}=0.011)$. The study revealed that older women were more likely to be screened compared to younger women. Table 4 present the summary of this analysis.

Table 4. Adjusted odds ratio of uptake of cervical cancer

\begin{tabular}{|c|c|c|c|c|c|c|c|}
\hline \multirow{2}{*}{ Variable } & \multirow{2}{*}{ B } & \multirow{2}{*}{ S. E. } & \multirow{2}{*}{ df } & \multirow{2}{*}{ Sig. } & \multirow{2}{*}{$\operatorname{Exp}(\mathbf{B})$} & \multicolumn{2}{|c|}{ 95\% C.I. for EXP(B) } \\
\hline & & & & & & Lower & Upper \\
\hline \multicolumn{8}{|c|}{ Age in complete years } \\
\hline \multicolumn{8}{|l|}{$18-25(\mathrm{RC})$} \\
\hline $26-33$ & 0.616 & 0.514 & 1 & 0.231 & 1.9 & 0.676 & 5.073 \\
\hline $34-41$ & 0.86 & 0.6 & 1 & 0.152 & 2.4 & 0.729 & 7.66 \\
\hline $42-49$ & 1.833 & 0.802 & 1 & 0.022 & 6.3 & 1.299 & 30.084 \\
\hline \multicolumn{8}{|c|}{ Highest level of education } \\
\hline \multicolumn{8}{|c|}{ Primary and less(RC) } \\
\hline Secondary & 0.128 & 0.47 & 1 & 0.785 & 1.1 & 0.453 & 2.853 \\
\hline Tertiary & 0.688 & 0.543 & 1 & 0.206 & 2 & 0.686 & 5.771 \\
\hline \multicolumn{8}{|l|}{ Marital status } \\
\hline \multicolumn{8}{|l|}{ Single(RC) } \\
\hline Married & 0.495 & 0.503 & 1 & 0.325 & 1.6 & 0.612 & 4.4 \\
\hline \multicolumn{8}{|l|}{ Number of children } \\
\hline \multicolumn{8}{|l|}{$1-2$ children $(\mathrm{RC})$} \\
\hline 3 or more children & 0.686 & 0.468 & 1 & 0.143 & 2 & 0.794 & 4.968 \\
\hline No children & -1.088 & 0.691 & 1 & 0.116 & 0.3 & 0.087 & 1.306 \\
\hline \multicolumn{8}{|l|}{ Occupation } \\
\hline \multicolumn{8}{|l|}{ Employed (RC) } \\
\hline Self employed & 0.473 & 0.414 & 1 & 0.253 & 1.6 & 0.713 & 3.615 \\
\hline Not employed & -1.241 & 1.165 & 1 & 0.287 & 0.3 & 0.029 & 2.834 \\
\hline \multicolumn{8}{|c|}{ Health insurance cover } \\
\hline \multicolumn{8}{|c|}{ Has cover(RC) } \\
\hline No cover & -0.62 & 0.397 & 1 & 0.119 & 0.5 & 0.247 & 1.172 \\
\hline \multicolumn{8}{|c|}{ Monthly income in Ksh } \\
\hline \multicolumn{8}{|l|}{ Up to $5000(\mathrm{RC})$} \\
\hline 5001-10000 & 0.526 & 0.471 & 1 & 0.264 & 1.7 & 0.673 & 4.256 \\
\hline more than 10000 & 0.177 & 0.526 & 1 & 0.737 & 1.2 & 0.426 & 3.346 \\
\hline Knowledge of cervi & & & & & & & \\
\hline Low knowledge( $\mathrm{RC}$ & & & & & & & \\
\hline High knowledge & 2.176 & 0.634 & 1 & 0.001 & 8.8 & 2.545 & 30.525 \\
\hline Offer of reading ma & & & & & & & \\
\hline Never(RC) & & & & & & & \\
\hline Rarely & 0.453 & 0.429 & 1 & 0.291 & 1.6 & 0.679 & 3.648 \\
\hline Frequently & 0.255 & 0.515 & 1 & 0.621 & 1.3 & 0.471 & 3.538 \\
\hline Advice by clinician & & & & & & & \\
\hline Never(RC) & & & & & & & \\
\hline Rarely & 1.113 & 0.467 & 1 & 0.017 & 3 & 1.219 & 7.604 \\
\hline Frequently & 1.345 & 0.534 & 1 & 0.012 & 3.8 & 1.348 & 10.924 \\
\hline Cultural and religio & & & & & & & \\
\hline Disagree(RC) & & & & & & & \\
\hline Agree & -1.209 & 0.737 & 1 & 0.101 & 0.3 & 0.07 & 1.264 \\
\hline Neutral & -0.041 & 0.675 & 1 & 0.952 & 1 & 0.255 & 3.607 \\
\hline Expense of cervical & & & & & & & \\
\hline Disagree(RC) & & & & & & & \\
\hline Agree & -0.248 & 0.461 & 1 & 0.59 & 0.8 & 0.316 & 1.925 \\
\hline Neutral & -1.092 & 0.501 & 1 & 0.029 & 0.3 & 0.126 & 0.895 \\
\hline
\end{tabular}




\section{Discussion}

Socio- demographic characteristics such as age, education, marital status, distance to health facility and occupation were found significant to the uptake of cervical cancer screening. Again, the area of residence was not found significant. This compares well with similar other studies [8].

Age was significant to the uptake to screening with majority of those screened being of age category 26-33 years $(46.9 \%)$. This category had the highest percentage that reported use of family planning methods (89\%). The National Cervical Cancer Prevention Plan targets women aged 25-49 for screening while excluding the school- going girls aged 18-24. Notable was the decrease in the rate of screening with advanced age where category 42-49 had the lowest rate of uptake with $10.9 \%$ having been screened. Advanced age was found to contribute to decreased use of screening services. A study in rural India showed older women were less responsive to screening arguing that screening made no difference whether found positive or negative [13]. This indicates the older women did not perceive any benefit of screening for cervical cancer.

The study found out that women education was significant to the uptake of cervical cancer screening. In this study, the highest number of screened women was those with tertiary level of education (48\%). This corroborates well with earlier findings that women with high screening rates have high level of education [14]. It was found out that most women were class 8 drop outs and had the highest non-uptake to cervical screening $(42.5 \%)$.

Marital status had significant influence on uptake to screening with $(85.9 \%)$ of those screened being married. Similar studies have shown association between being married and utilization of reproductive health services [14]. In this study, significant number of single women was aged 18-25 years, unemployed and perhaps cancer screening was not their priority.

The occupation of the respondents significantly influenced the uptake of cervical cancer screening. Majority of the respondents were employed and could afford to travel to far health facilities for cancer screening.

\section{Limitation}

Uptake of cervical cancer screening was based on a selfreported uptake in the respondents previous years of life. This is likely to suffer from recall biases as the respondents may report incorrectly. However, given the average age of the respondents and the fact that most of those who reported cervical cancer screened had done so in less than 3 years, the findings of this study are significant for programming purposes. Also only the respondents who sought health care services were interviewed, thus the findings did not include women who did not seek health services during the study period. However legible women seeking various services in the general outpatient department were included in the study.

\section{Conclusion}

The study found out that there is low rate of cervical cancer screening $(15.2 \%)$ in North Imenti sub-County. The main determinants of the uptake to screening were age, marital status, occupation, distance to health facilities and high level of education.

Married older women were more likely to be screened than younger women. Those with tertiary education were more likely to be screened than lower levels of education. Majority of those screened had formal employment and could afford to travel to far health facilities for the service.

\section{Recommendations}

Emanating from the findings, it is recommended that:-

- The Health Managers should increase the number of health facilities offering cervical cancer screening in order to extend uptake.

- Conduct regular refresher seminars for health workers in order to give updates and improve the skills for cervical screening.

- Intensify community health education through chiefs meetings (barazas) and school health talks on the benefits for cervical screening.

\section{Acknowledgement}

We sincerely thank all the women who voluntarily participated in this study plus the Health Managers of North Imenti sub- County for allowing this research to be conducted in the health facilities. More appreciations go to Prof. Mabel Nangami, Dr. Penina Masibo, and Mr. Andrew Muguna for their support, encouragement and guidance during the study. Lastly, we are indebted to all those who helped us directly or indirectly make this research a success.

\section{References}

[1] Bray, F., Ren, J.-S., Masuyer, E., \& Ferlay, J. (2013). Global estimates of cancer prevalence for 27 sites in the adult population in 2008. International Journal of Cancer, 132(5), 1133-1145. http://doi.org/10.1002/ijc.27711.

[2] Parkin, D. M., J. Ferlay, M. Hamdi-Cherif, F. Sitas, J. O. Thomas, H. Wabinga, and S. L. Whelan. 2003. Cancer in Africa-Epidemiology and Prevention. IARC Scientific Publications 153. Lyons: IARC Press.

[3] Nairobi Cancer Registry-NCR (2006); Cancer Incidence Report, Nairobi 2000-2002. Available from http://www.africacancer.org/downloads/cancer\%20incidence\% 20Report-KEMRI.pdf [accessed on 20/07/2010].

[4] Sherris, J., Herdman, C., \& Elias, C. (2001). Cervical cancer in the developing world. Western Journal of Medicine, 175(4), 231-233. 
[5] MOH: Ministry of Health: Review of the 2004-2008 reproductive health research agenda proposed 2010-2014 research agenda. 2010. WHO/ICO information Centre on HPV and Cervical cancer (2011). HPV and related cancers in Kenya summary report Retrieved on 31 January 2011 Online at www.who.int/hpvcentre.

[6] WHO/ICO: Human Papilloma Virus and related cancers in Kenya. In ICO Information Centre on HPV and Cancer. Geneva:

2010. http://www.hpvcentre.net/statistics/reports/KEN_FS.pdf (Accessed 31/07/2015).

[7] Gichangi, P., Estambale, B., Bwayo, J., Rogo, K., Ojwang, S., Opiyo, A., \& Temmerman, M. (2003). Knowledge and practice about cervical cancer and Pap smear testing among patients at Kenyatta National Hospital, Nairobi, Kenya. International Journal of Gynecological Cancer: Official Journal of the International Gynecological Cancer Society, $13(6), 827-833$.

[8] Were, E., Nyaberi, Z., \& Buziba, N. (2011). Perceptions of risk and barriers to cervical cancer screening at Moi Teaching and Referral Hospital (MTRH), Eldoret, Kenya. African Health Sciences, 11(1), 58-64.
[9] MOH, 2013, Meru County Referral Hospital annual report, https://hiskenya.org [accessed on 20/5/2013].

[10] MOH, 2012, National Cervical Cancer Prevention Program, Strategic Plan 2012-2015, http://www.iedeaea.org/joomla/attachments/article/304/National\%20Cervical\% 20Cancer\%20Prevention\%20Plan\%20FINALFeb\%202012.pd f.

[11] Cochran, W. G. (1977). Sampling techniques (3rd ed.). New York: John Wiley \& Sons.

[12] Yamane T. Statistics, An Introductory Analysis. 2nd ed. New York: Harper and Row, 1967.

[13] Nene, B., Jayant, K., Arrossi, S., Shastri, S., Budukh, A., Hingmire, S., Sankaranarayanan, R. (2007). Determinants of women's participation in cervical cancer screening trial, Maharashtra, India. Bulletin of the World Health Organization, 85(4), 264-272. doi: 10.2471/BLT.06.031195.

[14] Frida S Lyimo, T. N. B. (2012). Demographic, knowledge, attitudinal, and accessibility factors associated with uptake of cervical cancer screening among women in a rural district of Tanzania: three public policy implications. BMC Public Health, 12, 22. doi: 10.1186/1471-2458-12-22. 